\title{
UMA ANÁLISE ACERCA DOS CONTEÚDOS DE PEDOLOGIA NOS LIVROS DIDÁTICOS DE GEOGRAFIA DO ENSINO MÉDIO
}

\author{
Jamille Ramos ${ }^{(a)}$ Neianne Marinho ${ }^{(b)}$ Gustavo Barreto Franco ${ }^{(c)}$ \\ (a) Discentes do Curso de Licenciatura em Geografia, Universidade do Estado da Bahia, jaambs@ hotmail.com \\ (b) Professor assistente do curso de Geografia, Universidade Estadual da Bahia, gustavopraia@ yahoo.com.br
}

\section{EIXO: GEOGRAFIA FÍSICA: CURRÍCULO, FORMAÇÃO E PRÁTICAS DE ENSINO}

\begin{abstract}
Resumo
O presente artigo tem como objetivo analisar os conteúdos de pedologia nos livros didáticos de Geografia no Ensino Médio. Tendo em vista, que o livro didático é um dos recursos mais utilizados na sala de aula, é necessário compreender a veiculação dos conteúdos no processo de ensino-aprendizagem. Foram analisadas seis coleções de livros didáticos, todas contendo 3 volumes, onde foram averiguados conteúdos básicos da temática de Pedologia. Para a concretização da pesquisa, foi feita uma revisão bibliografia, análise da formação dos autores, identificação da ordem dos conteúdos, abrangência, fundamentação da informação, situação dos conceitos, atualização, relação conteúdo/realidade e linguagem. Foi identificado que em geral os conteúdos de Pedologia são pouco explorados e que as classificações de solo apresentadas não se enquadram no Sistema Brasileiro de Classificação dos Solos.
\end{abstract}

Palavras chave: Ensino de Geografia; Geografia Física; Livro Didático.

\section{Introdução}

O livro didático pode ser considerado como uma das ferramentas mais utilizadas na sala de aula, tendo um papel fundamental para o processo de ensino-aprendizagem, tornando-se um apoio para a construção do saber do aluno. Há um direcionamento dos conteúdos nos livros didáticos, ficando estabelecidos alguns caminhos para a preparação de aula. Nesse sentido, faz-se necessário uma escolha adequada para que a aprendizagem tenha maior significância. Sendo assim, o presente trabalho tem como objetivo analisar os conteúdos de Pedologia nos Livros didáticos de Geografia no Ensino Médio, a fim de compreender a sua veiculação nos livros.

O conteúdo pedológico no ensino de Geografia no Ensino Médio é de suma importância, pois o aluno precisa compreender e assimilar sobre a origem e formação dos solos, bem como compreender o uso e ocupação de onde vive. O estudo dos solos visa o desenvolvimento de uma sociedade, estando inserido: o processo de urbanização, aumento populacional, geração de demanda para o maior consumo de 
alimentos e conservação dos aquíferos. Nesse sentido, é preciso que o aluno entenda o solo como um recurso natural dinâmico, passível de ser degradado em função do uso inadequado do ser humano.

\section{Metodologia}

Os procedimentos metodológicos que essa pesquisa perpassou foram: revisão bibliográfica; seleção e análise de coleções dos livros didáticos; e levantamento dos conteúdos de Pedologia. Para a análise dos conteúdos foi considerado temas básicos, tais como: a) presença do conceito de solo, b) formação dos solos, c) descrição do perfil dos solos, d) classificação, e) conservação. As coleções que concretizam essa pesquisa foram: Fronteiras da Globalização (Coleção 1) - Editora Ática; Geografia - Espaço e Vivência (Coleção 2) - Editora Saraiva; Geografia - Sociedade e Cotidiano (Coleção 3) - Editora Escala Educacional; Geografia Geral e do Brasil (Coleção 4) - Editora Scipione; Ser Protagonista (Coleção 5) Organizadora Edições SM; Conexões Estudos de Geografia Geral e do Brasil (Coleção 6) - Editora Moderna. Ressalta-se que todos os livros foram aprovados pelo Programa Nacional do Livro para o Ensino Médio (PNLEM).

\section{Resultados e Discussão}

No que se refere às análises, a coleção 'Fronteiras da Globalização' inicia a discussão a partir do conceito de solo, sendo definido como parte mais superficial, e que comporta a vida. Quanto a formação dos solos os autores colocam que as variações de solos dependem de três aspectos, sendo eles: tempo, relevo e o tipo de rocha. Segundo Lepsch (2002), a existência de diferentes tipos de solos é controlada por cinco principais fatores: a) clima b) organismos c) material de origem d) relevo e) idade da superfície do terreno". Há uma abordagem sobre solos eluviais e aluvias. Os autores tratam horizontes e camadas como a mesma coisa. $\mathrm{O}$ assunto é tratado no volume 1 .

Na coleção "Geografia Espaço e Vivência”, o conteúdo de Pedologia encontra-se no volume 1, seguindo uma sequência de conteúdos sobre a formação terrestre o mesmo estando relacionado com os conteúdos de Geomorfologia e Hidrografia. De modo comparativo, o conteúdo de Pedologia é o menos trabalhado no livro, sendo resumido em duas páginas de modo superficial. O livro trata a importância do solo inicialmente, logo em seguida, aborda sobre a classificação dos solos, não adotando rigorosamente o Sistema Brasileiro de Classificação de Solos (2006). 
A coleção "Geografia Sociedade e Cotidiano" traz uma imagem de 2007, mostrando uma classificação Mundial dos Solos, usa os Biomas para fazer relação com os tipos de solo: Tunda, Podzólico e Pardo, Pradaria e Chernozen, Latossolos, Lixiviado sobre Floresta, Estepe, Deserto e Montanha. Essa Classificação é baseada pela União Internacional de Ciências do Solo (IUSS). Levando em consideração a escala do mapa 1/2500, a análise feita torna-se generalizadora, classificando o território brasileiro como Latossolo, "lixiviado sob floresta". O tema é tratado no volume 1 da coleção.

No volume 01 da coleção 'Geografia Geral e do Brasil”' o conteúdo inicia apontando que o conceito de solo se diferencia de acordo com cada ciência, tais como: geologia, engenharia, edafologia e pedologia. $\mathrm{O}$ livro segue a mesma perspectiva de Lepsch (2002) em que o solo vem a ser sinônimo de qualquer parte da superfície da Terra. Geólogos podem entendê-lo como parte de uma sequência de eventos geológicos. O engenheiro de obras, normalmente considera-o como parte da matéria-prima para construção de aterros, estradas, barragens. Os Químicos pode considera-lo como uma porção de material sólido.

No volume 1 da coleção "Ser Protagonista", é abordado inicialmente os três tipos de intemperismo, falando sobre sua influência na formação do relevo. Sobre o conceito de solo o autor define o solo como um corpo natural, claramente distinto do material rochoso, com presença de vida vegetal e animal. Quanto a formação dos solos há uma ênfase, mostrando os cinco fatores de formação, sendo bem explicado. De modo ilustrativo, os autores descrevem um perfil de solo e a sua evolução, abordando os conceitos de solo tais como: lixiviação e processo pedogenéticos.

O conteúdo de solos é encontrado com maior abrangência no volume 2 da coleção "Conexões Estudos de Geografia Geral e do Brasil”, no capitulo 4, os domínios naturais e os recursos hídricos. O conceito de solo é definido como resultado de partículas desagregadas e misturas de materiais orgânicos em decomposição (microrganismo, restos de plantas e animais) chamados de húmus. Sobre os elementos de formação o autor fala sobre solos zonais, interzonais e azonais. Em seguida destaca sobre a importância do solo para a sociedade, o conteúdo é apresentado em duas páginas.

\section{Considerações Finais}

Em base do que foi analisado, pode-se concluir que:

a) a coleção 5 apresenta uma abordagem mais ampla no que se refere a quantidade de páginas referente aos conteúdos de Pedologia. 
b) quanto às classificações de solo, são conteúdos existentes nas coleções, mas não se enquadra no Sistema Brasileiro de Classificação dos Solos, logo, algumas classes de solos brasileiras não se fazem presente nas coleções. Os tipos de solos mais citados em todas as coleções são o massapê e terra roxa.

c) sobre a conservação de solos, se fazem presentes em todas as coleções.

Quanto às recomendações, pede-se que os autores tenham atenção à atualização das classes de solos, para isso é necessária uma produção que atenda o Sistema Brasileiro de Classificações dos Solos, bem como insiram figuras atualizadas com o período de confecção dos livros.

\section{REFERÊNCIA}

ALBUQUERQUE, M. A. M. de; BIGOTTO, J. F; VITIELlO, M. A. Geografia sociedade e cotidiano. 3.ed. São Paulo: Escala Educacional, 2013.

ALMEIDA, L. M . A. de; RIGOLIN, T. B. Fronteiras da Globalização. 2. ed. São Paulo: Editora Ática, 2013.

ARAÚJO, L. T. R; GUIMARÃES, R. B. Conexões: estudos de Geografia Geral e do Brasil. 2. ed. São Paulo: Editora Moderna, 2013.

BOLIGIAN, A. T. A; BOLIGIAN. L. Geografia - Espaço e Vivência. 1. ed. São Paulo: Saraiva, 2010.

BRASIL. Parâmetros Curriculares Nacionais do Ensino Médio - PCNEM. Ministério da Educação: Brasília, 2000

EMBRAPA - CENTRO NACIONAL DE PESQUISA DE SOLOS - Sistema Brasileiro de Classificação de Solos. Brasília: EMBRAPA, 2006.

LEPSCH, I. F. Formação e Conservação dos Solos - São Paulo: Oficina de Textos, 2002.

MOREIRA, J. C; SENE, E. Geografia Geral e do Brasil: Espaço Geográfico e Globalização. 2. ed. São Paulo: Scipione, 2014.

MOREIRÃO, F. B. Ser protagonista: Geografia. 2. ed. São Paulo: Edições SM, 2013..

PLANO NACIONAL DO LIVRO DIDÁTICO PARA O ENSINO MÉDIO- PNLEM. Guia do livro didático. FNDE: Brasília, 2015. 